\title{
Extraction from Oily Sludge of Paraffinic Hydrocarbons with Gasoline as Solvent
}

\author{
P. Ze Bilo'o and M. B. Ngassoum
}

\begin{abstract}
From hazardous wastes produced in Petroleum Refineries, the most generated in large quantities is oily sludge. The use of gasoline for the extraction and characterization of paraffinic hydrocarbons from oily sludge was realized. The experimental design was applied to realize the extraction while the gas chromatographic method helped in the characterization of the paraffinic hydrocarbons. The results of extraction and characterization showed that the Ratio Solvent/Sludge has positive effect while Temperature and Contact time have negative effects on the effectiveness of the extraction process. $14825 \mathrm{ppm}$ is the highest concentration obtained through experimental conditions of Contact time $=\mathbf{3 0} \mathrm{min}$, Temperature $=40^{\circ} \mathrm{C}$, and Ratio $=6: 1.2,6,10,14-$ Tetramethylpentadecane (Pristane) is the compound having the highest concentration (2373 ppm) followed by 2-Methylhexadecane with a concentration of $848 \mathrm{ppm}$.
\end{abstract}

Index Terms - Paraffinic Hydrocarbons, Experimental design, Hazardous waste, Oily sludge, Paraffins.

\section{INTRODUCTION}

The remains found at the base of tank and other storage facilities are generally referred as sludge [1] which is constituted of considerable amounts of hydrocarbons, water and solid particles [2]-[4] and of mutagenic, carcinogenic, or poisonous compounds [4]-[7]. As the composition of crude oil varies, that is also how the one of the oily sludge varies as well as the one of the hydrocarbon fraction. Great amount of high molecular weight paraffinic hydrocarbons were found in Cameroonian oily sludge [8], [9]. The crude oil production companies' usually face pipeline transport issues of the desirable lighter paraffins due to heavy paraffins that often drop on the inner parts of production equipment and on the walls of tubing [10].

Knowing that products like petrolatum are manufactured heavy paraffins, our study is orientated toward the recovery of paraffinic hydrocarbons in oily sludge from Cameroon Petroleum Refining Company. This work have as objectives to bring out the effect of some physical parameters on the recovery of paraffinic hydrocarbons from oily sludge with a fraction of commercialized gasoline used as solvent and to characterize the extracts by identifying and quantifying the compounds that were extracted from the Cameroonian oily sludge.

Submitted on January 27, 2021.

Published on February 19, 2021.

B. P. Ze, Faculty of Mines and Petroleum Industries (FMIP), The University of Maroua, Cameroon.

(e-mail: zebiloop@ ${ }^{@}$ yhoo.fr)

\section{MATERIAL AND METHODS}

A. Material

Studied oily sludge were sampled and prepared as described by Ndjeumi et al. [11]. Its average constitution was as follows: $25.36 \%$ of hydrocarbons, $2.20 \%$ of fine particles, and $72.45 \%$ of water [9].

\section{B. Methods}

\section{1) Solvent Preparation}

For the recovery of aliphatic hydrocarbons from Cameroonian oily sludge, the commercialized gasoline, cut into three (03) fractions were used as solvent. Obtained from a fuel station, the sample of gasoline went through a fractional distillation. The ranges of temperatures used were $\mathrm{T}_{1}<70^{\circ} \mathrm{C}$, $\mathrm{T}_{2}=70-110^{\circ} \mathrm{C}$ and $\mathrm{T}_{3}>110^{\circ} \mathrm{C}$. The gas chromatography as described by Ze and Ngassoum [8] were used to analyze the various obtained fractions. $T_{2}$ was chosen after the analysis of the fractions to be used as solvent for the paraffinic hydrocarbons recovery based on an experimental design.

\section{2) Paraffinic hydrocarbons extraction}

The composite factorial plan with centered faces experimental design was used to conduct the extraction of paraffins. The influence of three different parameters studied (contact time, temperature, and solvent/sludge ratio) on the aliphatic hydrocarbon recovery were the purpose of the research. Upper and lower limits of the three parameters of the experimental design could be fixed based on the literature, and are as presented in the below Table 1.

TABLE I: FACTORS AND EXPERIMENTAL DOMAINS

\begin{tabular}{lccc}
\hline \hline \multicolumn{1}{c}{ Factors } & Units & Designations & $\begin{array}{c}\text { Experimental } \\
\text { domains }\end{array}$ \\
\hline Solvent/Sludge ratio & $/$ & $\mathrm{A}$ & $2: 1-6: 1$ \\
Temperature & ${ }^{\circ} \mathrm{C}$ & $\mathrm{B}$ & $40-60$ \\
Contact time & Minutes & $\mathrm{C}$ & $30-90$ \\
\hline \hline
\end{tabular}

The way the experimental design was made up brought out a total of 16 manipulations among which two analyses at the center. The calculation was done following the Equation 1 below:

$$
\mathrm{N}=2^{\mathrm{k}}+2 \mathrm{k}+2=2^{3}+2 * 3+2=16
$$

Each of the 16 obtained extracts went through the experiments as described by Ze Bilo'o and Ngassoum [8]. In

M. B. Ngassoum, Laboratory of Industrial Chemistry and Bioressources (LICB), National School of Agro-Industrial Sciences (ENSAI), The University of Ngaoundere, Cameroon. (e-mail: ngassoum ${ }^{@}$ yahoo.fr) 
order to acquire the spectra, and to be able to identify and quantify the hydrocarbon compounds in each extracts, the software Peak sample 432-64bit was used. The percentages of groups of recovered compounds and the mass of the extract $(\mathrm{mg})$ are the two responses observed from the experimental design.

\section{RESULTS AND DISCUSSION}

\section{A. Solvent Preparation}

The spectra obtained by chromatographic analysis brought out a list of compounds that were classified into families (aromatic compounds, linear, cyclic, and ramified paraffins) and the fraction containing heptane and its various isomers was selected. Heptane was chosen as selection parameter since it has been used as solvent by Zubaidy and Abouelnasr [12] for hydrocarbon recovery. The Figure 1 illustrates the graphic representation of the amounts of ramified paraffins and aromatic compounds that keeps increasing with the temperature range. Comparatively to Kerosene [11], aromatic compounds are abundantly present in Gasoline while linear and cyclic paraffins are reduced. It has been noted that the amounts of linear and cyclic paraffins reached their highest amount in the temperature range of $70-110^{\circ} \mathrm{C}$. In the other hand, it is in the range $70-10^{\circ} \mathrm{C}$ that heptane and its isomers are highly present. Paraffinic hydrocarbons molecules in this fraction are in the range of 6 carbons (Methylcyclopentane) to 11 carbons (2-Methyldecane).

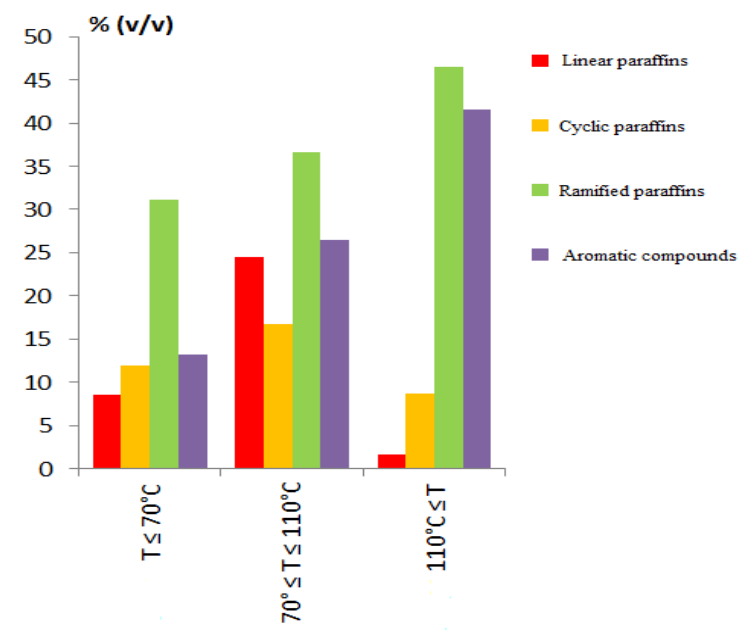

Fig. 1. Amount of families of compounds present in each fraction of Gasoline.

\section{B. Aliphatic Hydrocarbons Recovery}

\section{1) Study parameters effect of on the recovery}

The assessment the effect of the three studied parameters (A: Solvent/Sludge ratio, B: Temperature, and C: Contact time) on the recovery of aliphatics based to the experimental design was done and the various extracted masses were recorded. The standardized Pareto graphic (Fig. 2) could be plotted after the analysis of values obtained. It is noted that only the Solvent/Sludge ratio and its interaction with Temperature has a significant positive effect on paraffin extraction with an important weight. Temperature, contact time and interaction ratio-contact time have negative effect with an important weight on the mass of recovered paraffins. This graphic shows that, practically, the more the ratio and its interaction with temperature increase the extracted mass, the more contact time and the temperature should be reduced gradually. The equation model (2) below is confirming the previous statement with the coefficient of each factor representing their weight. By contrary with the results of Ndjeumi et al. [11] who had positive significant effect while working with Kerosene, the temperature and the interaction between Ratio and Contact time have significant negative effect on the extraction effectiveness.

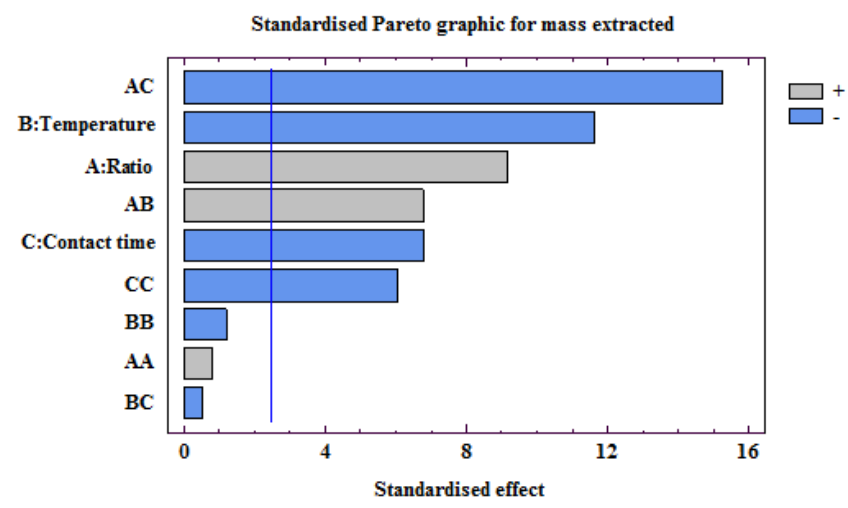

Fig. 2. Paraffins recovery standardized Pareto graphic.

$$
\begin{gathered}
\mathrm{Y}=1.455+0.776 \mathrm{~A}-0.989 \mathrm{~B}-0.575 \mathrm{C}+0.644 \mathrm{AB}- \\
1.449 \mathrm{AC}-0.051 \mathrm{BC}+0.130 \mathrm{~A}^{2}-0.198 \mathrm{~B}^{2}-1.004 \mathrm{C}^{2}(2)
\end{gathered}
$$

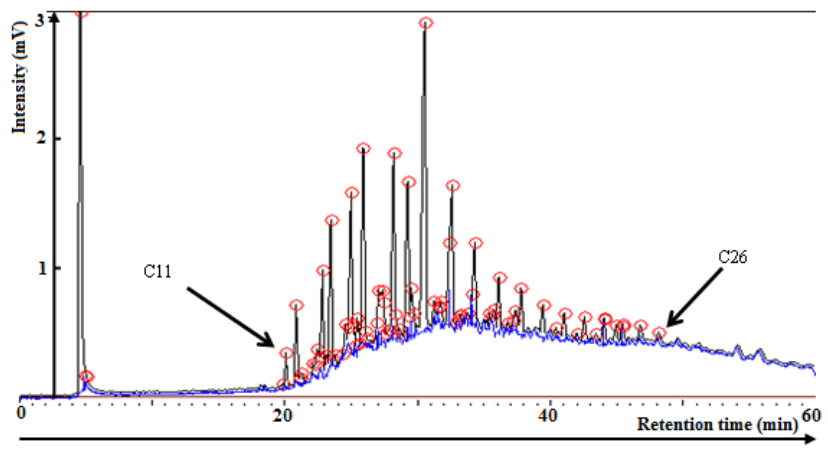

Fig. 3. Spectra of recovered paraffinic hydrocarbons under experimental conditions of Ratio $=6: 1$, Temperature $=40^{\circ} \mathrm{C}$, Contact time $=30 \mathrm{~min}$.

\section{2) Composition of recovered hydrocarbon fraction}

The software Peak sample 432-64bit associated to GC-FID were used to acquire the spectra of all analyzed extracts, and to characterize each extract by identifying and quantifying the hydrocarbon content. A similarity of shape of spectra were noticed even though only the intensity and number of peaks were different. The Figure 3 above shows the chromatogram obtained at experimental conditions of Ratio=6:1, Temperature $=40{ }^{\circ} \mathrm{C}$, Contact time $=30 \mathrm{~min}$.

The spectra illustrated that, mixed with some unidentified hydrocarbon compounds, the paraffinic hydrocarbons recovered and identified have the number of carbons atoms ranged from eleven (11) to twenty-six (26). By contrary, it was observed that [11] the number of carbons of extracted aliphatic hydrocarbons ranged from eight (8) to twenty eight (28). Based on their structure, the extracted aliphatic hydrocarbons were identified, quantified, and classified. The classification is linear aliphatics, aliphatics with one, two, three, and more than three ramifications, cyclic aliphatics and non-identified aliphatics. 
The highest total concentration of extracted paraffins was $14825 \mathrm{ppm}$, obtained under experimental conditions of Contact time $=30 \mathrm{~min}$, Ratio $=6: 1$, Temperature $=40{ }^{\circ} \mathrm{C}$, while the least concentration was obtained at Contact time $=$ $30 \mathrm{~min}$, Ratio $=2: 1$, Temperature $=60{ }^{\circ} \mathrm{C}$. The 2,6,10,14Tetramethylpentadecane (Pristane) which is a homologous of heptadecane is the compound having the highest concentration (2373 ppm) followed by 2-Methylhexadecane with a concentration of $848 \mathrm{ppm}$. The Table 2 below illustrates the proportions of the various groups in each extract. With Gasoline, it was observed that [11] 2,6Dimethyldecane followed by 2,6-Dimethylundecane were the most extracted paraffins.

The concentrations of families in all extracts were determined. The highest extraction obtained with the fraction of Gasoline for each give concentrations of $3005 \mathrm{ppm}$ (linear aliphatics), $4622 \mathrm{ppm}$ (aliphatics with one ramification), and 1345 ppm (aliphatics with two ramifications) under experimental conditions of Contact time $=30 \mathrm{~min}$, Ratio $=$ 6:1, and Temperature $=40{ }^{\circ} \mathrm{C}$. Aliphatics with three ramifications $(551 \mathrm{ppm})$ and above $(2923 \mathrm{ppm})$, led to the highest concentrations under Ratio $=6: 1$, Temperature $=$ $50{ }^{\circ} \mathrm{C}$, Contact time $=60 \mathrm{~min}$. These last results could are justified by the fact that the molecular structure of these compounds with heavy molecular weight need higher temperature and contact time for their dissolution and diffusion to take place. With the fraction of Kerosene [11] used as solvent, the amounts extracted for each group of paraffins are far away grater. Based on recovery conditions, the corresponding compound family that is the most recovered is presented in Table 3. It came out that the amount of recovered solid paraffinic hydrocarbons having more than 16 atoms of carbon was higher in each extract compare to liquid paraffinic hydrocarbons.

Standardized Pareto graphic illustrated that the Temperature has a negative influence on the effectiveness of the recovery. The increase of Temperature from $40{ }^{\circ} \mathrm{C}$ to $60{ }^{\circ} \mathrm{C}$ at constant Ratio (6:1) and Contact time (30 min) decreases the concentrations of the various families of paraffins to $2497 \mathrm{ppm}, 3747 \mathrm{ppm}, 1273 \mathrm{ppm}, 102 \mathrm{ppm}$, and 2757 ppm respectively for linear aliphatics, aliphatics with one ramification, aliphatics with two ramifications, aliphatics with three ramifications and aliphatics with more than three ramifications. The quality and the quantity of aliphatics recovered are also strongly associated to the constitution of the solvent since the one used is a mixture of compounds which some have been used as solvent when pure.

TABLE II: RATIO OF RESPECTIVE ALIPHATIC GROUPS IN EACH EXTRACT

\begin{tabular}{|c|c|c|c|c|c|c|c|c|c|c|c|c|c|c|c|c|}
\hline $\begin{array}{c}\text { Designation } \\
\text { (Ratio - } \\
\text { Temperature - } \\
\text { Contact time) }\end{array}$ & 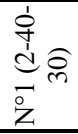 & 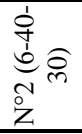 & 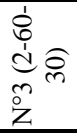 & 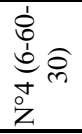 & 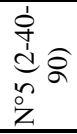 & 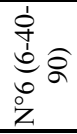 & 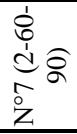 & $\begin{array}{l}\text { d } \\
0 \\
1 \\
1 \\
\infty \\
0 \\
i\end{array}$ & 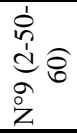 & 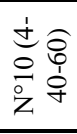 & 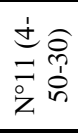 & 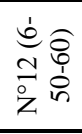 & 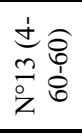 & 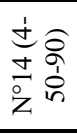 & 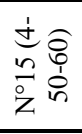 & 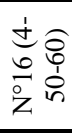 \\
\hline TPS (ppm) & 311 & 14825 & 92 & 13203 & 4997 & 9290 & 1695 & 1820 & 386 & 447 & 1832 & 11994 & 9118 & 8671 & 7633 & 7579 \\
\hline LP $(\%)$ & 41.48 & 20.27 & 27.17 & 18.91 & 13.77 & 12.41 & 7.14 & 11.15 & 21.50 & 22.82 & 16.81 & 18.62 & 21.33 & 17.91 & 21.52 & 21.59 \\
\hline P1R (\%) & 20.26 & 31.18 & 29.35 & 28.38 & 32.68 & 28.16 & 22.54 & 22.75 & 29.53 & 27.52 & 32.53 & 32.08 & 32.07 & 30.15 & 32.57 & 32.48 \\
\hline P2R (\%) & 6.75 & 9.07 & 0.00 & 9.64 & 5.26 & 5.89 & 5.07 & 12.80 & 6.99 & 6.04 & 4.53 & 6.45 & 6.72 & 6.77 & 5.86 & 5.94 \\
\hline P3R (\%) & 4.18 & 0.63 & 7.61 & 0.77 & 3.44 & 3.60 & 6.13 & 5.16 & 6.22 & 4.70 & 1.91 & 4.59 & 3.55 & 5.18 & 5.03 & 5.04 \\
\hline $\mathrm{P}+3 \mathrm{R}(\%)$ & 27.33 & 19.27 & 35.87 & 20.88 & 20.47 & 18.62 & 15.52 & 14.18 & 29.02 & 24.38 & 24.24 & 24.37 & 18.81 & 23.23 & 19.34 & 19.45 \\
\hline $\mathrm{CP}(\%)$ & 0.00 & 0.32 & 0.00 & 0.58 & 0.25 & 0.42 & 0.00 & 0.00 & 0.00 & 0.00 & 0.00 & 0.24 & 0.50 & 0.46 & 0.10 & 0.08 \\
\hline UP (\%) & 0.00 & 19.26 & 0.00 & 20.84 & 24.13 & 30.90 & 43.60 & 33.96 & 6.74 & 14.54 & 19.98 & 13.65 & 17.02 & 16.30 & 15.58 & 15.42 \\
\hline
\end{tabular}

TPS = Total Paraffins in the Sample; LP = Linear Paraffins; P1R = Paraffins with 1 ramification; P2R = Paraffins with 2 ramifications; P3R = Paraffins with

3 ramifications; $\mathrm{P}+3 \mathrm{R}=$ Paraffins with more than 3 ramifications; $\mathrm{CP}=\mathrm{Cyclic}$ Paraffins; $\mathrm{UP}=$ Unidentified Paraffins.

TABLE III: MAXIMUM CONCENTRATION RECOVERED, AND OPTIMAL EXPERIMENTAL CONDITIONS FOR EACH GROUP OF ALIPHATICS

\begin{tabular}{|c|c|c|c|c|c|}
\hline $\mathrm{N}^{\circ}$ & Groups of paraffins & $\begin{array}{c}\text { Maximum } \\
\text { concentration } \\
\text { extracted }(\mathrm{ppm})\end{array}$ & $\begin{array}{l}\text { Optimal } \\
\text { ratio }(\%)\end{array}$ & $\begin{array}{c}\text { Optimal } \\
\text { temperature }\left({ }^{\circ} \mathrm{C}\right)\end{array}$ & $\begin{array}{l}\text { Optimal contact } \\
\text { time }(\mathrm{min})\end{array}$ \\
\hline 1 & Linear Paraffins & 3005 & 6 & 40 & 30 \\
\hline 2 & Paraffins with 1 ramification & 4622 & 6 & 40 & 30 \\
\hline 3 & Paraffins with 2 ramifications & 1345 & 6 & 40 & 30 \\
\hline 4 & Paraffins with 3 ramifications & 551 & 6 & 50 & 60 \\
\hline 5 & Paraffins with more than 3 ramifications & 2923 & 6 & 50 & 60 \\
\hline 6 & Cyclic Paraffins & 77 & 6 & 60 & 30 \\
\hline
\end{tabular}

\section{CONCLUSION}

The assessment on the effect of three parameters on the aliphatics hydrocarbons recovery from Cameroonian oily sludge with a fraction of commercialized gasoline showed that all of them have a significant influence, on the effectiveness of the recovery, may it be positive (Ratio Solvent/Sludge) or negative (Temperature and Contact time). The qualitative and quantitative analysis of compounds that can be recovered from the Cameroonian oily sludge were achieved. It appeared that the aliphatics with one ramification are highly recovered (4622 ppm) at a Contact time of $30 \mathrm{~min}$, Ratio of $6: 1$, and Temperature of $40{ }^{\circ} \mathrm{C}$. The observed differences with results obtained when Kerosene is used as solvent can primarily be attributed to the constitution of the fraction used as solvent. In fact, the constituents in each fraction of solvent (Gasoline and Kerosene) have specific affinity with compounds of hydrocarbons present in the oily sludge.

\section{ACKNOWLEDGMENT}

The authors are grateful to the National Petroleum Refinery of Cameroon for providing samples and to the Laboratory of Industrial Chemistry and Bioressources of the National School of Agro-Industrial Sciences (ENSAI) of The University of Ngaoundere for the help in some analytical measurement. 


\section{REFERENCES}

[1] Olufemi AJ, Augustine CA. Petroleum sludge treatment and disposal: A review. Environ. Eng. Res. 2019;24:191-201.

[2] Lucena E, Verdun P, Aurelle Y, Secq A. Nouveau procédé de valorisation des "slops » de raffineries et déchets huileux par distillation hétéroazéotropique. Oil \& Gas Science and Technology Rev. IFP 2003;58:353-360.

[3] Lingsheng Z, Jiang X., Liu J. Characteristics of Oily Sludge Combustion in Circulating Fluidized Beds. J. Hazard. Mater. 2009; 170:175-179.

[4] Baochen C, Fuyi C, Jing G, Xu S, Huo W. and Liu S. Oxidation of Oily Sludge in Supercritical Water. J. Hazard. Mater. 2009;165:511-517.

[5] Chun-Teh L, Wen-Jhy L, Hsiao-Hsuan M, Chun-Ching S. PAH Emission from the Incineration of Waste Oily Sludge and PE Plastic Mixtures. The Science of the Total Environment, 1995;170:171-183.

[6] Al-Futaisi A, Jamrah A, Yaghi B, Taha R. Assessment of Alternative Management Techniques of Tank Bottom Petroleum Sludge in Oman. J. Hazard. Mater. 2007;141:557-564.

[7] Ayotamuno MJ, Okparanma RN, Nweneka EK, Ogaji SOT, Probert SD. Bio-remediation of Sludge Containing Hydrocarbons, Appl. Energ. 2007;84:936-943.

[8] Ze Bilo'o P, Ngassoum MB. Characterization of Polycyclic Aromatic Hydrocarbons (PAHs) in oily sludge from Cameroon petroleum refinery. Inter. J. Environ. Sci. 2012;3:509-517.

[9] Ze Bilo'o P, Ngassoum MB, Jessie Ekoka CS. Characterization of oily sludge from Cameroon petroleum refinery, Inter. J. Emerg. Eng. Res. and Technol. 2016;4:34-38.

[10] Zhang J, Li JB, Thring RW, Hu X, Song XY. Oil recovery from refinery oily sludge via ultrasound and freeze/thaw. J. Hazard. Mater. 2012;203-204:195-203.

[11] Ndjeumi CC, Ze Bilo'o P, Mouthe GAA, Ngassoum MB. Aliphatic Hydrocarbons Extraction from Oily Sludge using Kerosene. European J. Eng. Res. Sci. 2020;5:1137-1141.

[12] Zubaidy EAH, Abouelnasr DM. Fuel recovery from waste oily sludge using solvent extraction, Process. Saf. Environ. Protect. 2010;88:318326.

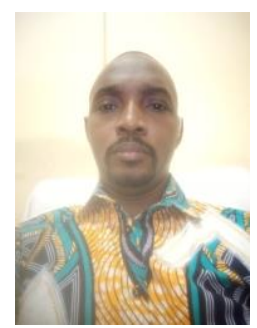

Z. E. BILO'O Philemon was born in Sangmelima, Cameroon. Holder of a Masters of Engineering in Industrial Agro Food Processes, a Masters in Industrial and Environmental Chemistry, and a $\mathrm{PhD}$ in Industrial and Environmental Chemistry in the National School of Agro-Industrial Sciences (ENSAI), The University of Ngaoundere, Cameroon. His major fields of studies are Petroleum and petroleum waste, Industrial Processes, and Environment depollution.

$\mathrm{He}$ is co-author of several publications in the scientific journals. He is interested in environmental pollution by hydrocarbons and remediation; Water treatment and Improvement of industrial processes, and Depollution Processes, waste management and Environmental protection. 